\title{
IDENTIDADES INTRANSIGENTES EM A PIANISTA DE ELFRIEDE JELINEK
}

Dionei Mathias ${ }^{1}$

Resumo: Este artigo tem por fim refletir sobre o processo de construção de identidade no romance A Pianista, escrito por Elfriede Jelinek. Nele, a autora austríaca cria personagens cujas identidades podem ser caracterizadas como discursos repressivos e autoritários que procuram impor sua interpretação de realidade por meio de mecanismos de vigilância e uso de violência. Palavras já não representam um instrumento de diálogo, mas sim de poder intransigente. Seu questionamento implica perseguição.

Palavras-chave: Elfriede Jelinek, Die Klavierspielerin, A Pianista.

Abstract: This article aims to reflect on the process of identity construction in the novel The Piano Teacher written by Elfriede Jelinek. In it, the Austrian author creates characters whose identities can be characterized as repressive and authoritarian discourses, trying to impose their reality interpretation by means of surveillance mechanisms and use of violence. Words no longer represent an instrument of dialogue, but rather of intransigent power. Their questioning implies persecution.

Keywords: Elfriede Jelinek, Die Klavierspielerin, The Piano Teacher.

\section{Introdução}

No início estava a palavra. Palavra etimologicamente vem de parábola, uma justaposição de dois mundos, de duas realidades, que, por meio da comparação, unifica, aparentemente, o ser em si e sua materialização simbólica. A palavra devém instrumento de representação, de instauração de realidade, que impõe uma interpretação do mundo (ABELS, 2009). Dependendo do grau de intransigência do instaurador, essa palavra se torna lei inflexível ou dogma inquestionável, num extremo. Noutro, ela se desfaz em vestígios de significados a serem atualizados ininterruptamente. A concatenação causal de palavras se transforma em discursos, em modos, portanto, de conceber o espaço social e existencial. Os detentores de poder instauram a palavra e, com elas, os discursos

\footnotetext{
${ }^{1}$ Professor Adjunto do Departamento de Letras Estrangeiras Modernas na UFSM.
} 
que formam a base narrativa da realidade. O sujeito e sua consciência se encontram imersos nesses emaranhados discursivos e, desde seus primeiros ensaios de simbolização, buscam sentidos para dar conta da realidade e inserir-se nela (ZIMA, 2000; KEUPP, 2002). Nisso figuram dois discursos especialmente importantes: a narração da nação e sua ideologia por um lado e a narração do eu por outro. Dois extremos, poder-seia dizer, duas ficções dentre diversos discursos, dos quais o sujeito não logra esquivar-se.

Como a palavra, o discurso pode apresentar um grau maior ou menor de intransigência. Assim, estados totalitários não toleram o questionamento de sua ideologia nem consentem revisões de sua narração, portanto perseguem e aniquilam todos aqueles que não apóiam sua interpretação de realidade ou aqueles que procuram subverter sua versão de mundo. Narrações identitárias inflexíveis, no outro extremo, tampouco admitem versões alternativas de autorrepresentação, lançando mão de diversas estratégias de subjugação para refrear encenações socialmente não sancionadas. Em ambos os casos, estigmatização social e humilhação representam estratégias discursivamente imbricadas, por vezes de forma nuançada, para garantir a observância da ideologia oficial e a prática de narrações identitárias em consonância com a interpretação tradicional. Se esses instrumentos de violência verbal não surtem o efeito tencionado, aplica-se a violência física como forma de ameaça à integridade do corpo, garantindo desse modo a continuação da interpretação de realidade vigente num determinado espaço social (GINZBURG, 2012, p. 53). Essa experiência - como processo de interação - conforme apontam Umbach/Calegari/Ourique (2012, p. 8), permeia, de uma forma ou outra, todas as sociedades, patenteando o caráter protéico do fenômeno de heteronomia.

Tendo em vista a violência e as aberrações de autoritarismo que perpassam a composição de diversas personagens da obra da autora austríaca Elfriede Jelinek, este artigo tem por fito refletir sobre a encenação de identidade de duas personagens centrais do romance $A$ Pianista, escrito em 1983. Nessa obra, a detentora do Prêmio Nobel de Literatura cria figuras altamente desconcertantes, personagens que estão imersas em conflitos de gerações (WIGMORE, 2007, p. 295), que refletem resquícios do comportamento nazista (SCHLIPPHACKE, 2010, p. 86) ou que revelam anseios incestuosos sufocantes (WRONSKA, 2009, p. 158). Por um lado, a senhora Kohut, a mãe autoritária e intransigente que procura manipular a filha ininterruptamente; por outro, 0 


\section{Literatura e Autoritarismo}

Identidade, memória e representações culturais

aluno e pretendente Klemmer, que vê sua masculinidade em risco ao defrontar-se com os desejos, para ele, inusitados de sua professora. Entre essas duas fontes de repressão e imposição da palavra instauradora de realidade, encontra-se Erika Kohut, a professora de piano, que longe de incorporar somente uma vítima, é incapaz de libertar-se das garras maternas e das imposições de seu corpo. Tanto a senhora Kohut como o aluno Klemmer procuram impor narrações totalizantes que não permitem quaisquer questionamentos. Ao verem seus discursos identitários ameaçados, lançam mão da violência para impor à força sua versão de realidade.

\section{A figura materna e o cerceamento do espaço identitário}

Carcereira, espiã, controladora, a senhora Kohut impera incondicionalmente sobre o espaço social e existencial da filha, exigindo desta uma submissão completa, sem espaço para projetos identitários que não condigam com as expectativas da matriarca. $\mathrm{A}$ despeito dos mais de trinta anos da filha, de sua independência financeira e de sua formação intelectual, a mãe não hesita em definir o que a filha deve vestir, com quem deve sair e que esperanças tem de alimentar quanto a seu futuro pessoal. Para garantir um controle completo, até mesmo divide a cama com Erika, de maneira que não lhe resta nem mesmo um espaço íntimo para esquivar-se da escrutinação materna. O convívio sufocante, repressor e autoritário sob a vigilância disciplinadora da matriarca molda o comportamento da professora de piano:

Erika tornou-se ágil por necessidade. Como um enxame de folhas de outono carregadas pelo vento, ela entra pela porta em alta velocidade e tenta alcançar seu quarto sem ser vista. Mas a mamãe já está postada bem ali e exige-lhe explicações. Inquisidora e pelotão de fuzilamento em uma só pessoa, reconhecida unanimemente pelo Estado e pela família como mãe, ela a põe contra a parede e a obriga a falar. Já faz três horas que o último aluno voltou para casa, depois de ter sido ridicularizado por ela. Acha que eu não sou capaz de descobrir onde você esteve, Erika. Uma filha deve satisfação à sua mãe - e antes mesmo que a mãe peça. 
Mas a mãe não acredita, porque a filha gosta de mentir. A mãe ainda espera, mas conta apenas até três (JELINEK, 2011, p. 9-10). ${ }^{2}$

As imagens utilizadas para descrever o comportamento de Erika patenteiam sua necessidade existencial de idear estratégias para subtrair-se ao cerco ininterrupto organizado pela mãe. Essa necessidade se revela eminentemente impositiva, porquanto o espaço de circulação e desenvolvimento existencial não the advém de forma livre e espontânea. Não se trata de um espaço que lhe permite experimentar identidades em conformidade com seus anseios íntimos, tecer e entrelaçar linhas narrativas de uma filigrana extravagante, fundir e mesclar unidades significativas autônomas e absolutamente próprias. A figura materna se impõe tal qual um estado totalitário, sem qualquer sinal de indulgência para com as excentricidades da filha. Poder executivo, legislativo e judiciário numa única pessoa, a mãe controla, interroga e força a fala, sem conceder espaços de refúgio que possibilitem ilhas de autonomia ${ }^{3}$. Diante do silêncio subversivo e insubmisso, recorda-Ihe a eficiência e onipresença de seu aparato de vigilância e aponta a ameaça de destruição, forçando o corpo da filha, receoso da dor, a reagir prontamente, reafirmando sem delongas, por sua vez, o poder absoluto da palavra inexorável expelida pela fonte materna.

Esse poder absoluto, no entanto, não teria efeito se, ademais de impor sua lei por meio da ameaça, não contasse também com o respaldo do espaço social no qual está inserido. A instituição 'mãe' e todas as ações oriundas de seu seio são legitimadas de forma automática e cabal pelo meio social, de forma que seu comportamento não se vê forçado a passar pelo crivo de uma instância reguladora externa. Sua palavra instaura a lei e tem de ser cumprida sem titubeios. Esse parâmetro de acesso e interpretação de realidade está inscrito indelevelmente no subconsciente de Erika, aflorando à consciência em forma de reminiscências tão logo se distancia daquilo que fora sancionado pelo estado materno: "Um tapa da mãe zumbe sobre o piano porque a posição das mãos da criança não estava certa. Lembranças imperecíveis brotam da inesgotável caixa craniana

\footnotetext{
${ }^{2}$ Citações de acordo com a tradução de Luis S. Krauz. Elfriede Jelinek. A pianista. São Paulo: Tordesilhas, 2011. Em nota de roda-pé, encontra-se a indicação da respectiva passagem no original alemão: Elfriede Jelinek. Die Klavierspielerin. Reinbek bei Hamburg: Rowohlt, 1986. Aqui (1986, p. 7).

${ }^{3}$ Em seu artigo, Elizabeth Wright (1999, p. 51-59) parte da imagem "monte de terra" (JELINEK, 2011, p. 32) - no original "Lehmklumpen" (JELINEK, 1986, p. 27) - para delinear contundentemente a estética do asco e do abjeto inscrita na obra. Essa mesma imagem materializa imageticamente o poder quase que absoluto da mãe que se arroga o direito de moldar o objeto inerte e amorfo que saiu de suas entranhas, sem concederlhe a liberdade de tomar decisões sobre seu próprio corpo.
} 
de Erika" (JELINEK, 2011, p. 256) ${ }^{4}$. Ou seja, a mãe logra apropriar-se da matriz de instauração de realidade e identidade, ao garantir, por meio da implantação de mecanismos de controle no âmago do ser, que sua filha conforme suas ações e leituras em consonância com os desejos maternos.

Lá se for preciso, pode-se chamá-la por telefone. Ou, para sua alegria, Erika está com colegas de seu próprio feitio, tocando música de câmara e jubilando. E então pode-se chamá-la por telefone. Ela luta tenazmente contra os laços maternos e tenta não ser chamada por telefone, mas a mãe facilmente consegue transpor essas barreiras, pois é ela quem define os mandamentos, sozinha. É também quem define quem pode ou não procurar pela filha. O resultado disso é que há cada vez menos pessoas que desejam vê-la ou falar com ela (JELINEK, 2011, p. 12) ${ }^{5}$.

A reiteração quase que maníaca da possibilidade de contatá-la por telefone corrobora, não a feliz oportunidade de poder comunicar-se a qualquer momento com sua filha, antes, simboliza um instrumento de poder do qual a instância materna se utiliza para controlar todos e quaisquer movimentos realizados pela filha. Dessa forma, ela logra potenciar seu serviço de inteligência e - mais uma analogia ao estado totalitário - controlar também sua rede social, de forma a evitar possíveis encontros indesejados que pudessem constituir um núcleo de subversão da narração oficial.

A mãe, no entanto, não se contenta somente com a imposição de seus mandamentos, ela quer igualmente moldar o desejo da filha, de maneira que sua encenação como fonte única e inexorável de leis que imperam sobre o espaço existencial da filha se Ihe inscrevam na carne, adentrando assim a volição visceral: "A vontade de Erika será a ovelha que se aconchega no leão da vontade materna. E por causa desse gesto de submissão a vontade da mãe se abstém de esfrangalhar a vontade pouco ilustrada da filha e de sacudir entre os dentes seus ossos ensangüentados" (JELINEK, 2011 , p. 227) ${ }^{6}$. A violência não se explicita somente nas imagens ensanguentadas da carne dilacerada, ela se franqueia, sobretudo, na constante violação do espaço íntimo, no cerceamento da liberdade pessoal por meio de instrumentos de vigilância contínua, na apropriação agressiva de estratos da consciência e de até mesmo de impulsos vitais. A mãe impõe à filha sua interpretação da realidade, ela a força a construir uma identidade

\footnotetext{
${ }_{5}^{4}$ (JELINEK, 1986, p. 230).

${ }^{5}$ (JELINEK,1986, p. 9-10).

${ }^{6}$ (JELINEK,1986, p. 203).
} 
de acordo com seus preceitos e a obriga a agir e interagir em consonância com seus projetos de futuro. Em seu estudo, Janz (1995, p. 74) aponta que a mãe, incapaz de criar um eu próprio, tampouco permite que a filha desenvolva uma personalidade autônoma. Esta, receosa do excesso de complexidade que a existência impõe sem a palavra conducente da mãe, abdica, de fato, de sua individualidade a fim de transformar-se em objeto da volição materna, um objeto reprodutor, sem espaço para modificação ou adaptação, da ideologia ideada pela senhora Kohut. Diante desse cenário, a filha serve de instrumento para a formação de identidade da mãe, sem direito a narrações próprias. Para garantir que Erika se conforme a essa função e adapte sua própria narração de maneira a cumprir esse fim, a mãe instila sua ideologia nas redes simbólicas de Erika já nos primeiros ensaios de consciência, criando posteriormente um aparato de controle para manter o estado desejado. Desse modo, a narração de identidade repressora e autoritária da mãe devém o discurso oficial que logra reduzir a complexidade e aparentemente explicar o fenômeno da realidade de forma cabal e contundente.

\section{O macho assustado: irrupções indesejadas na narração oficial}

A segunda personagem com a qual Erika interage intensamente é seu aluno Klemmer. Diligente e interessado, este se aplica aos estudos com o fito de conquistar a atenção da professora a despeito da enorme diferença de idade que os separa. Ciente disso e, sobretudo, da possível insegurança que esse aspecto possa exercer na encenação pessoal da professora, ele se aproxima dela com o propósito de manobrá-la em direção às suas vontades. Estas se reduzem exclusivamente à possibilidade de instrumentalização da professora como objeto sexual temporário. Indiferente às possíveis projeções para o futuro que a professora possa desenvolver no tocante a uma narração teleológica comum e suas respectivas implicações para a construção de identidade, Klemmer se concentra em adquirir sua confiança para que dessa forma possa alcançar seus objetivos de forma mais célere. 
Encoberta por trás desse maquiavelismo erótico, encontra-se uma encenação de identidade embasada em imagens tradicionais e inquestionáveis de superioridade masculina (LÜCKE, 2008, p. 75). A partir dessa concepção de narração pessoal do homem como princípio motor de instauração de realidade e de instância deliberante quanto à imposição do desejo, todo o processo de conquista do corpo feminino nada mais é que um prelúdio gentil à disposição do objeto. A palavra masculina, na visão de mundo de Klemmer, define as coordenadas de interpretação e as diretrizes de ação, por conseguinte, sua atenção à mulher 'Erika' representa um ato condescendente que, em seus rodeios aparentemente diplomáticos, procura dissimular sua superioridade para não magoar a sensibilidade da professora de piano. A gentileza inicial com a qual se aproxima de Erika se revela, pois, como um instrumento discursivo maquinado sutilmente para enredar a atenção de seu objeto de interesse, obliterando de todas suas ações toda sorte de humanismo que pudesse divisar no outro um ser autônomo, imbuído de dignidade e merecedor de respeito. Imerso nessa visão de mundo, Klemmer se surpreende quando deparado com uma mulher que está longe de submeter-se a seus caprichos e permanecer passiva, sem articular desejos próprios e muito bem definidos.

Ao revelar-lhe seus anseios eróticos, evidenciando dessa forma uma autonomia inesperada, a identidade masculina do aluno sofre uma primeira fragmentação. Em sua versão estática de identidade, a expressão do desejo parte do homem; sua voz prescreve e instaura o pensável e o factível, portanto a realidade. Quando Erika lhe expõe suas fantasias masoquistas por meio de uma carta de cuja leitura ele tenta esquivar-se, uma voz alternativa irrompe em seu mundo, obrigando-o a repensar os nexos causais que concatenam sua narração identitária:

De má vontade ele tira Erika de suas mãos já abertas e rasga o envelope. Atônito, lê alguns trechos em voz alta. Se o que está escrito naquela carta for verdade, a coisa está malparada para ele, mas ainda muito pior para a mulher. Isso ele garante. Apesar de todo seu empenho, agora ele não consegue mais vê-la como um ser humano. Só se pode tocar uma coisa assim de luvas. [...]

Klemmer explica que muitas vezes é preciso coragem para recusar um desafio e se decidir pelo normal. Klemmer é a norma. Ele lê e se pergunta o que essa mulher estará imaginando. Será que essa carta dever ser levada a sério ${ }^{7}$ Quanto a ele, isso é a pura verdade ${ }^{8}$, que ele conheceu

\footnotetext{
${ }^{7}$ Uma tradução alternativa: "Será que ela [Erika] está falando a sério?".
} 


\section{Literatura e Autoritarismo}

nas corredeiras, onde muitas vezes se corre perigos verdadeiros e se aprende a dominar situações (JELINEK, 2011, p. 243) ${ }^{9}$

O impacto que a carta causa é tamanho, que ele se vê forçado a idear uma interpretação imediata em consonância com sua visão de mundo para salvar sua narração pessoal. $\mathrm{O}$ primeiro movimento nessa direção se revela em sua tentativa de minorar Erika como ser humano. O desprezo e o asco, legitimados a partir dos discursos oficiais acerca de preferências sexuais imagináveis, Ihe permitem manter sua posição de superioridade. Já antes de ler a carta, em sua visão de mundo, ela não passava de um objeto do qual queria dispor a seu bel-prazer; depois da leitura não o é menos ("uma coisa assim"), mas agora, coisificada, de forma consciente como instrumento de autoencenação moral, corroborando - para ele - a irrepreensibilidade de seu modelo de mundo em contraposição ao comportamento ignominioso adotado por ela. Ou seja, em ambos os momentos, Erika não passa de objeto, mas a forma como ele insere a presença desse objeto em sua narração pessoal muda de acordo com as suas necessidades narrativas.

No segundo momento de sua argumentação, Klemmer tenta salvar sua imagem, enfatizando a virilidade necessária, ao optar pela norma. Para encobrir seu desconcerto e manter sua visão de mundo intocada, ele aduz sua capacidade paternalista de discernimento no tocante à propriedade de comportamentos, divisando com acuidade os limites entre normalidade e abjeção. A norma reside em sua interpretação do certo, revelando, portanto, reiteradamente a arbitrariedade inscrita em sua utilização de discursos. Enquanto Erika tem de se ater incondicionalmente às normas, ele pode moldálas de acordo com seus caprichos. Num terceiro momento de seu raciocínio, ele questiona a seriedade daquilo que Erika Ihe propõe. Se de alguma forma ele pudesse interpretar os acontecimentos de modo a imputar a Erika uma menoridade crítica, uma infantilidade moral ou uma insuficiência cognitiva, sua narração paternalista e sua identidade tradicional estariam a salvo. Este não sendo o caso, ele tem de assumir seu papel cultural de homem e garantir que a tradição não seja maculada, o que para ele, afeito a dominar os turbilhões da natureza, é uma questão de seriedade absoluta. Todos esses movimentos iniciais ainda revelam um certo pendor a condescender com gracejos

\footnotetext{
${ }^{8} \mathrm{O}$ tradutor optou por traduzir "blutiger Ernst" com "pura verdade". Uma alternativa menos elegante: "seriedade seriíssima".

9 (JELINEK,1986, p. 218).
} 
da mulher, contestando desse modo qualquer autonomia da qual Erika possa, de fato, querer se servir.

Ao dar-se conta que Erika não o disse em tom jocoso, que, ao contrário, ela the propõe algo de igual para igual, desconstruindo, por conseguinte, sua posição paternalista por meio de implicações, ele se apercebe de que sua narração de identidade está em risco. Para isso, ele abandona seu comportamento condescendente e parte para as diversas formas de violência, com o fito de romper o desejo autônomo de Erika e reaver sua interpretação de realidade. Tendo a sociedade como respaldo, ele aduz uma escala de valores na qual o comportamento da professora figura como algo necessariamente digno de rejeição. Encenando seu desprezo, pois, ele reafirma sua superioridade moral, garantindo por momentos, sua posição no campo de poder e de produção discursiva: "Klemmer afirma que não a tocaria nem mesmo com um alicate. Ele jura que antes havia amor, mas que agora já não há mais. E que ele não voltará a procurá-la. Ela o apavora. Como ela pode sugerir uma coisa dessas! [...] E ele afirma que não bate nela porque não quer sujar suas mãos" (JELINEK, 2011, p. 260) ${ }^{10}$. O corpo antes desejado e cuja presença era bem-vinda nas interações socialmente permitidas repentinamente se transforma em abjeto a ser evitado para não macular a própria imagem. O desejo alternativo - não previsto, muito menos sancionado na narração tradicional - devém estigma de cuja irradiação contagiosa, aparentemente, é mister afastar-se. Suas ponderações ou hesitações, no entanto, revelam a flexibilidade dos parâmetros que ele aponta como inexoráveis, ou seja, o estigma, por sua vez, se torna instrumento de resgate de autoencenação. Para potenciar o efeito de seu desprezo, ele a abandona em silêncio: "Klemmer não diz não temos mais nada a dizer um ao outro. Sem se despedir, ele sai e bate a porta atrás de si. E logo em seguida já foi embora" (JELINEK, 2011, p. 261-262 $)^{11}$. Envolvendo seus pensamentos e suas ações numa nuvem de silêncio, ele evita trair seu desconcerto e assegura que a produção de signos ou da interação discursiva permaneça em suas mãos.

A despeito desses primeiros movimentos de autoproteção, Klemmer já não logra mais desfazer-se das impressões despertadas pela carta da professora. Uma visão

\footnotetext{
${ }_{11}^{10}$ (JELINEK, 1986, p. 234).

11 (JELINEK, 1986, p. 235).
} 
alternativa irrompeu em seu mundo e, para que a integridade de sua identidade não sofra uma descontinuidade impassível de ser integrada na concatenação causal de sua visão de mundo, produzindo uma sensação de contingência insofrível, ele tem de destruir o discurso que se lhe impõe de forma inesperadamente subversiva. Essa irrupção desconcertante de alteridade em seu discurso homogêneo e aparentemente irreduzível fica ainda mais conspícua quando, ao reencontrar Erika, tenta encenar o "macho insaciável" para quem o papel da mulher se reduz a servir-lhe de objeto de prazer. O ato sexual se desenrola em meio a cenas grotescas, reproduzindo a submissão da mulher diante dos desmandos masculinos. Inesperado para Klemmer, no entanto, é que, a despeito dessa encenação tradicional da distribuição de papéis e de poder, seu vigor masculino o desaponta (JELINEK, 2011, p. 273-279) ${ }^{12}$, patenteando de certa forma sua incapacidade de integrar em sua visão de mundo a presença de uma mulher e, com ela, de um discurso que questiona seu acesso à realidade. Para existir nesse espaço social, ele precisa de uma visão totalizante e demanda, sem meandros, uma submissão completa, sem quaisquer questionamentos, por parte daqueles que adentram suas coordenadas narrativas. Seu refúgio perante o inegável é o instrumento da humilhação: "Ela deveria sumir da cidade para que ele não fosse obrigado a respirar, com suas jovens e novas narinas, o cheiro repelente e bem peculiar que ela exala, esses vapores animalescos de podridão. Que nojo! A senhora nem pode imaginar como a senhora fede, professora" (JELINEK, 2011, p. 279) ${ }^{13}$. Questionando humanidade da professora, ele aparentemente mantém a incolumidade de seu próprio ser e evita pensar sobre si.

A humilhação como mecanismo de contenção de narrações indesejadas e de refreamento de processos de autorreflexão, não obstante, não surte o efeito planejado. Dessa insuficiência nasce a necessidade, de forma ainda mais exacerbada, de inscreverse na realidade de Erika, de forma a marcar-lhe na carne que sua autoridade e, sobretudo, sua palavra permanecem como princípio da lei. Por conseguinte, depois da cena grotesca de caça aos flamingos (JELINEK, 2011, p. 283) ${ }^{14}$ em que pretende matar as aves como forma de ab-reação dos ímpetos agressivos que o acometem, ele se dirige à casa de Erika a fim de impor sua visão por meio de violência física: "Para que ele possa

\footnotetext{
12 (JELINEK, 1986, p. 244-250).

${ }_{14}^{13}$ (JELINEK, 1986, p. 250-251).

${ }^{14}$ (JELINEK, 1986, p. 254).
} 
avançar em sua vida e em seus sentimentos, essa mulher, que chegou a rir dele em momentos em que ainda triunfava um pouco, precisa ser destruída" (JELINEK, 2011, p. 304) ${ }^{15}$. Klemmer experimenta, com uma premência cada vez maior, a necessidade de obliterar o corpo de cuja fonte provêm as palavras que ameaçam sua narração, uma vez que se imiscuem de maneira inextricável na filigrana de sua consciência, forçando-o a idear o insofrível.

De modo a desterrá-las ao calabouço do impensável, ele adentra a casa da professora esbofeteando-a, para depois dar sequência a uma série de agressões que lhe permitam reafirmar sua imagem de superioridade:

Ninguém pode dizer que você é jovem, Erika, não é verdade? Ele é jovem. Ela é velha. Ele é homem. Ela é mulher. Walter Klemmer chuta animadamente as costelas de Erika, que está deitada no chão. Ele dosa a sua força para que nada se quebre. Pelo menos o seu próprio corpo ele sempre dominou. Pelo umbral de Erika, Walter Klemmer passa para a liberdade. Ela mesma o desafiou a fazê-lo, pois tentou dominar a ele e seus desejos. E isso é o que ela conseguiu (JELINEK, 2011, p. 305) ${ }^{16}$.

De sua disposição desigual das coordenadas de poder, deflue sua autopercepção de superioridade inabalável, porquanto - sendo jovem e homem - não há o que possa debilitar seu corpo como fonte de realidade. Para dar sustento à sua convicção, ele a agride, atentando a não deixar vestígios que pudessem comprometê-lo no espaço social a que pertence. De modo covarde não atípico a sistemas totalitários, ele se protege duplamente: por um lado, evitando vestígios que o forçassem a assumir a responsabilidade pelos seus atos diante de um tribunal de justiça, por outro, escudandose diante de seu foro interior, ao delegar a responsabilidade de sua atitude, deslocando a culpa para o comportamento de Erika. Diante desse raciocínio, a professora pecou por recusar sua submissão passiva e impor questionamentos que subvertem a narração oficial (de Klemmer), ao arrogar-se o direito de querer, de algum modo, influenciar seus desejos.

A liberdade que Klemmer experimenta por meio da violência é a intuição da ruína ética. Sem barreiras discursivas represando seu potencial agressivo, o corpo alheio se

\footnotetext{
${ }^{15}$ (JELINEK, 1986, p. 273).

${ }^{16}$ (JELINEK, 1986, p. 274).
} 
torna objeto absoluto a ser disposto de forma ilimitadamente arbitrária: "Em meio aos pontapés ele prova à mulher que eu sou o resultado da conta. E não me envergonho nem um pouco disso ${ }^{17}$. Assim como eu sou, eu sou. Erika teve luxados o osso do nariz e uma de suas costelas com os pontapés" (JELINEK, 2011, p. 306) ${ }^{18}$. Se o resultado da equação de fato se reduz à igualdade do eu a despeito das interações com o meio, a figura 'Klemmer' enfatiza seu anseio - na prática, insustentável - de encenar uma narração de identidade absoluta que se recusa a integrar signos que não provenham de sua própria matriz discursiva. Para manter a pureza de seu eu imaculada e impor seu discurso identitário como bloco de essências metafísicas, ele tem de necessariamente destruir tudo aquilo que, de algum modo, se infiltra em sua palavra intransigente. O resumo lacônico "assim como eu sou, eu sou" não representa um ato de resignação perante suas insuficiências pessoais, mas sim uma asserção que enfatiza a desnecessidade de justificar seus atos, legitimando o princípio da arbitrariedade.

\section{Considerações finais}

A intransigência da palavra, imposta por sistemas totalitários de explanação de realidade, representa um mecanismo de proteção discursiva que tem seu início no seio do ser. A narração da identidade absoluta se transforma num primeiro ensaio de imposição discursiva de realidade, concatenando causas e efeitos num emaranho narrativo que não prevê alternativas ou espaços vazios. Para garantir a aceitação da palavra articulada na encenação de identidade totalitária, o sujeito lança mão de mecanismos de controle e vigilância, mas também de agressão física e verbal para assegurar a submissão dos membros envolvidos. O sujeito imerso nessas narrações alheias tem duas opções: submissão ou subversão.

\footnotetext{
${ }^{17}$ No original, a frase reza "Er beweist der Frau unter Tritten die einfache Gleichung ich bin ich. Und ich schäme mich dessen nicht" (JELINEK, 1986, p. 275). Uma tradução alternativa da primeira frase: "Em meio aos pontapés ele demonstra à mulher a simples equação 'eu sou eu'". Com a obliteração da letra 't' na pronúncia final da palavra "nicht" surge uma rima entre as duas frases que corrobora ainda mais o desprezo por princípios de humanidade inerente às palavras de Klemmer. ${ }^{18}$ (JELINEK, 1986, p. 275).
} 
Encurralada entre dois discursos repressores e totalizantes, a personagem Erika é composta por ações que procuram esquivar-se dessas imposições concretizadas pela mãe ou por Klemmer. Mas a despeito de seus ensaios de ruptura, a narração materna está indelevelmente inscrita nos primórdios de sua consciência, de modo que não logra pensar a realidade senão com a matriz discursiva que lhe foi instilada em seus primeiros exercícios de simbolização. Inconscientemente, portanto, ela repete a interpretação que Ihe foi pré-disposta, como é possível depreender das frases finais do romance "Erika sabe o caminho que deve tomar. Vai para casa. Ela vai e aos poucos acelera seu passo" (JELINEK, 2011, p. 318) ${ }^{19}$. As fronteiras da narração materna marcam seus próprios limites. Aquilo que se encontra além dessas coordenadas representa dor, a dor da repressão, mas também a dor do conscientemente suportável.

\section{Referências}

ABELS, Heinz. Wirklichkeit. Über Wissen und andere Definitionen der Wirklichkeit, über uns und Andere, Fremde und Vorurteile. Wiesbaden: VS Verlag für Sozialwissenschaften. 2009.

GINSBURG, Jaime. Crítica em tempos de violência. São Paulo: EDUSP, 2012.

JANZ, Marlies. Elfriede Jelinek. Stuttgart/Weimar: Verlag J. B. Metzler, 1995.

JELINEK, Elfriede. A pianista. Tradução Luis S. Krauz. São Paulo: Tordesilhas, 2011.

JELINEK, Elfriede. Die klavierspielerin. Reinbek bei Hamburg: Rowohlt, 1986.

KEUPP, Heiner et alia. Identitätskonstruktionen. Das Patchwork der Identitäten in der Spätmoderne. Reinbek bei Hamburg: Rowohlt. 2002.

LÜCKE, Bärbel. Elfriede Jelinek. Paderborn: Wilhelm Fink Verlag, 2008.

SCHLIPPHACKE, Heidi. Nostalgia alter Nazism: History, Home and Affect in German and Austria Literatura and Film. Lewisburg: Bucknell, 2010.

UMBACH, R. K., CALEGARI, L. C., OURIQUE, J. L. P. Violência \& Memória na produção cultural: o autoritarismo na Alemanha e no Brasil. Santa Maria: PPGL UFSM. 2012.

${ }^{19}$ (JELINEK, 1986, p. 285). 
WIGMORE, Juliet. 'Sex, Violence and Schubert: Michael Haneke's La Pianiste and Elfriede Jelinek's Die Klavierspielerin'. In: Processes of Transposition: German Literature and Film. Ed. Christiane Schönfeld e Hermann Rasche. Amsterdam: Rodopi. 2007, p. 293-306.

WRIGHT, Elizabeth. 'Eine Ästhetik des Ekels: Elfriede Jelineks Roman 'Die Klavierspielerin". In: Text + Kritik: Zeitschrift für Literatur, 117, 1999, p. 51-59.

WRONSKA, Olga. 'Le Crime d'Olga Arbélina versus La Pianiste d'Elfriede Jelinek: Vers une poétique psychanalytique de l'inceste'. In: Andrei Makine. Ed. Murielle Lucie Clement. Ámsterdam: Rodopi. 2009, p. 157-165.

ZIMA, V. Peter. Theorie des subjekts. Tübingen/Basel: A. Francke Verlag. 2000. 